\title{
Study of caesium-137 in surface waters and sediments of the Tagus river
}

\author{
A. Baeza, A. Brogueira', C. Miro and M. Sequeira ${ }^{1}$ \\ Universidad de Extremadura, Facultad de Veterinaria, \\ Departamento de Fisica, 10071 Caceres, Spain \\ ${ }^{1}$ Instituto Tecnologico e Nuclear, Departamento de Protecçao Radiologica \\ e Segurança Nuclear, Estrada Nacional 10, 2686-953 Sacavém Codex, Portugal
}

\begin{abstract}
We have quantified the caesium-137 in surface waters and sediments in both the Portuguese and the Spanish sections of the Tagus River over six years. This river has its source in Spain, and of its $1100 \mathrm{~km}$ length about $230 \mathrm{~km}$ are in Portugal, $43 \mathrm{~km}$ serving as a natural frontier between the two countries. In the two regions under study the water flow is completely regulated by a chain of dams. There are three nuclear power plants, along the Spanish section of the river that might be sources of radioactive contamination. The Almaraz Nuclear Power Plant (ANPP) is the radioactive release source closest to Portugal. A concentration gradient of caesium was observed in the water, with the maximum values occurring at the sampling sites near the ANPP. However, there was no dependence of the caesium concentrations measured in the sediments on the proximity to the source. Instead, the values were related to the sediment type and its particle size. Distribution coefficients were evaluated in order to compare the radionuclide concentrations in water and sediments. In the calculation we took into account the time the caesium takes to move between these two media.
\end{abstract}

\section{INTRODUCTION}

The radioisotope ${ }^{137} \mathrm{Cs}$ is among the most widely distributed long-lived fission products in the environment. Its presence in environmental samples is most often due to nuclear weapon tests, but it is also released from nuclear power plants. The Almaraz Nuclear Power Plant (ANPP), located in the Extremadura region of Spain, is cooled with water from the artificial Arrocampo reservoir, which takes water from, and releases it into, the Torrejón reservoir on the Tagus River. This river has its source in Spain, and of its $1100 \mathrm{~km}$ length about $230 \mathrm{~km}$ are in Portugal, $43 \mathrm{~km}$ serving as a natural frontier between the two countries. In these two countries, the water flow is completely regulated by a chain of dams. The Tagus River might receive radioactive contributions from another two nuclear power plants, Zorita and Trillo, situated close to Madrid. However, ANPP is the radioactive release source closest to Portugal (Figure 1).

Previously data have been reported by the two laboratories of the authors of the present study separately, on samples collected during the period 1986-89 [1,2]. Also the authors have studied jointly the spatial and temporal evolution of the levels of tritium along this river [3].

The objective of this work is to quantify the caesium-137 in surface waters and sediments in both the Portuguese and Spanish sections of the Tagus River, during 1994-99, analysing the interaction between the waters and the sediments. To this end, we shall study this radionuclides transit time between the two receptors, determining whether the ${ }^{137} \mathrm{Cs}$ concentrations in the water influence those in the sediments, or vice versa, and whether any such influence is direct or inverse. Lastly, we determine the distribution coefficients at the different sampling points. To quantify these aspects, mathematical techniques applied to the study of time series were used.

\section{EXPERIMENTAL}

\subsection{Study Area}

As can be seen in Figure 1, ANPP is situated in the province of Cáceres (Spain) $180 \mathrm{~km}$ westsouthwest of Madrid, on the right bank of the Tagus River whose waters are indirectly used for cooling. It is a PWR-type plant, with two 930 MWe reactors that came on-line in 1981 and 1983.

The water flow of the Tagus in its passage through the province of Cáceres (Spain) and the Alentejo and Ribatejo regions (Portugal) is completely regulated by a chain of dams. The Valdecañas dam, with a $500 \mathrm{hm}^{3}$ capacity, is located upstream of the ANPP discharge point into the Torrejón reservoir (capacity $166 \mathrm{hm}^{3}$ ). Downstream are located the Alcántara reservoir, normal volume $1600 \mathrm{hm}^{3}$ and the Cedillo reservoir, $255 \mathrm{hm}^{3}$, the latter forming the frontier with Portugal. Now within Portugal, there are the reservoirs of Fratel, normal volume $82 \mathrm{hm}^{3}$ and Belver, $100 \mathrm{hm}^{3}$, in the Alentejo and Ribatejo regions, respectively. These reservoirs are designed mainly for hydroelectric production, but the Torrejón reservoir also has the mission of supplying water to the Arrocampo reservoir to cool the ANPP. To maintain the volume of Arrocampo practically constant at $35 \mathrm{hm}^{3}$, and also its water temperature relatively constant and sufficiently low, water is transferred between the Torrejón and Arrocampo 
reservoirs, and there is a forced circulation of the water around the Arrocampo reservoir at a constant rate of $88 \mathrm{~m}^{3} / \mathrm{s}$.

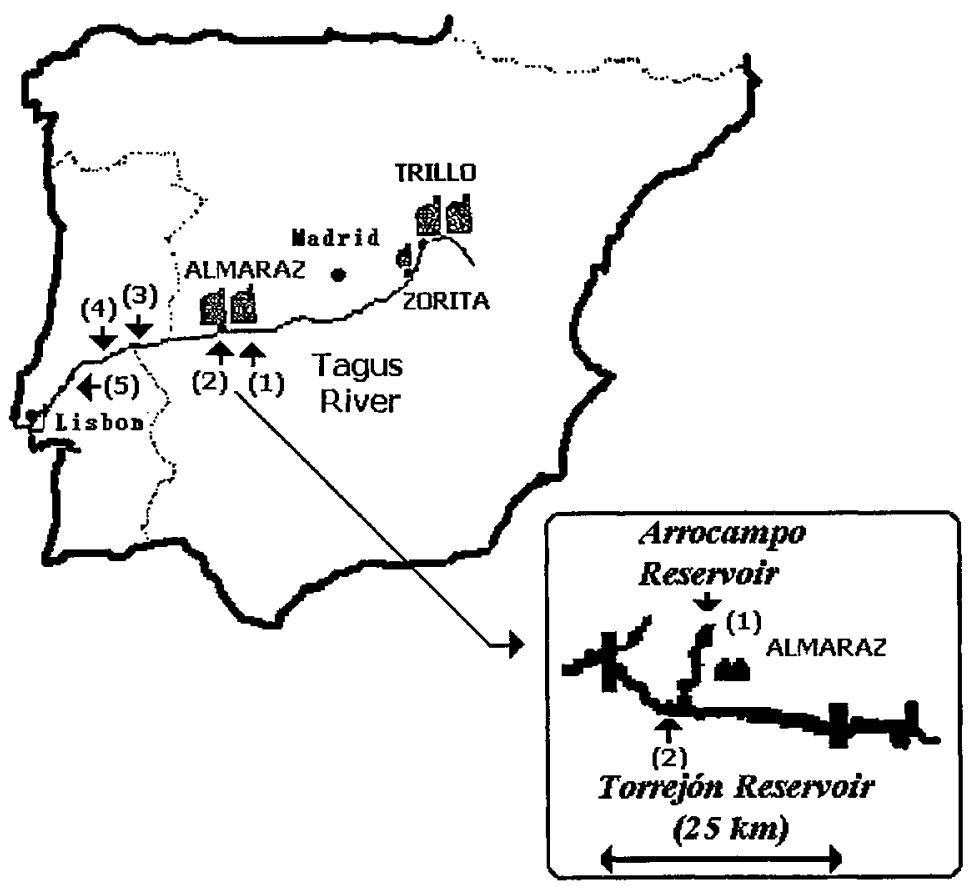

Figure 1: Map of Spain and Portugal, showing the Tagus River with the locations of the sampling points.

\subsection{Sampling points}

Samples were collected monthly, from 1994 to 1999, at 5 different points whose locations are given in Figure 1. Sampling points in Spain are: (1) in the ANPP cooling reservoir itself, which will call Arrocampo; (2) in the Torrejón reservoir, downstream from the Arrocampo dam but close to the outlet from that reservoir into the Torrejón reservoir, identified as Torrejón. The sampling points in Portugal are: (3) in the Fratel reservoir, at about $35 \mathrm{~km}$ from the frontier and immediately upstream from the town Vila Velha de Rodao, identified as V.V. Rodao; (4) also in the Fratel reservoir, but approximately $500 \mathrm{~m}$ upstream from the dam, identified as Fratel; (5) at $90 \mathrm{~km}$ downstream from the Fratel point, downstream from the Belver dam, with the sampling point being close to the mouth of the Tagus in Lisbon, identified as Valada, where there is an uptake of water destined for the consumption of that city.

\subsection{Analytical methods}

After collection the water samples were immediately acidified to $\mathrm{pH} 1$, and passed through a 0.45 $\mu \mathrm{m}$ pore size filter of cellulose membranes.

In the Spanish laboratory, 20 liter of initial volume were evaporated to dryness for the ${ }^{137} \mathrm{Cs}$ determination. The residue was collected and measured by gamma-spectrometry .

In the Portuguese laboratory, 30 liter of the initial volume of the sample, were evaporated to dryness and the organic matter digest with nitric acid and hydrogen peroxide. A caesium carrier was added. The caesium was extracted with ammonium phosphomolybdate in an acidic medium. After several radiochemical separations, the caesium was precipitated in the form of caesium chloroplatinate, and then determined by beta measurements in a low-background counter, calibrated with sources prepared from standard solutions. 
In both laboratories, the sediment samples were collected not far from the river bank, and were dried at $110^{\circ} \mathrm{C}$. The $2 \mathrm{~mm}$ total sediment fraction was taken for the present study and measured by gamma spectrometry.

Both laboratories performed the gamma-spectrometry with Ge semiconductor detectors coupled to a 4096-channel analysers. The detectors were calibrated using certified mixed gamma standards (energy range $60-1900 \mathrm{keV}$ ). Activities of ${ }^{137} \mathrm{Cs}$ were calculated from the $661.6 \mathrm{keV} \_$peak.

The analytical procedures and the detectors of both laboratories were cross-checked to ensure that their results were comparable.

\section{RESULTS AND DISCUSSION}

\subsection{Annual average values}

Table 1 presents the mean annual values $\left(\mathrm{Bq} / \mathrm{m}^{3}\right)$ of ${ }^{137} \mathrm{Cs}$ in water for the various sampling points, as well as the mean values for the total time period covered by the study, together with their standard deviations.

Table 1: Annual average values of ${ }^{137} \mathrm{Cs}$ concentrations $\left(\mathrm{Bq} / \mathrm{m}^{3}\right)$ in water of the Tagus River

\begin{tabular}{|c|l|l|l|l|l|}
\hline Year & Arrocampo & Torrejónn & V.V. Rodao & Fratel & Valada \\
\hline 1994 & 2.2 & 1.6 & 2.2 & 2.0 & 0.6 \\
1995 & 3.3 & 1.6 & 1.7 & 1.6 & 1.3 \\
1996 & 3.0 & 1.9 & 0.7 & 0.5 & 0.6 \\
1997 & 6.3 & 2.0 & 2.1 & 1.5 & 1.1 \\
1998 & 2.0 & 0.7 & 1.8 & 1.8 & 1.3 \\
1999 & 1.2 & 1.8 & 1.7 & 1.5 & 0.9 \\
\hline Total Average & $3.02 \pm 2.89$ & $1.57 \pm 1.45$ & $1.52 \pm 1.14$ & $1.48 \pm 1.18$ & $0.98 \pm 0.71$ \\
\hline
\end{tabular}

One deduces from this table that the ANPP is a source of release by way of the water, since the greatest concentrations are found in the plant's cooling reservoir, Arrocampo. In the Torrejón reservoir there is already a lower concentration of this radionuclide, and from this point downstream there is a decreasing gradient of concentration in the water along the course of the Tagus River towards its mouth.

It is worth noting that, despite Valada being the closest sampling point to the mouth of the Tagus River and the sea, and despite the level of the waters there oscillating with the tides, there is no mixture of the water at this point with sea water. This is shown by the fact that the ${ }^{137} \mathrm{Cs}$ levels are the lowest of the section of river that was studied, and if there had been any mixing, one would have observed a change in the levels of this radionuclide due to the alteration in salinity.

The ratio between the mean ${ }^{137} \mathrm{Cs}$ values in water measured at Arrocampo and Valada is 3:1. Thus, the dilution of this radionuclide along the length of the river is less than that observed for tritium which was found to be about 20 for the two most widely separated sampling points [3]. This may be interpreted on the basis of the smaller relative increment over standard environmental radioactive background levels produced by the ANPP for ${ }^{137} \mathrm{Cs}$ with respect to ${ }^{3} \mathrm{H}$.

The values found for ${ }^{137} \mathrm{Cs}$ in waters of the Spanish section of the Tagus River from 1994-99 are higher than those found for 1986-89, when we obtained a mean value at Arrocampo of $0.82 \mathrm{~Bq} / \mathrm{m}^{3}$ [2]. In the Portuguese zone of the river, however, there was no difference in the values for these two time periods [1]. In any case, the levels are similar to those found in other European rivers affected by liquid releases from nuclear facilities [4-6]. Nevertheless, our values surpass those of the Ebro River in Spain, which are always below $0.6 \mathrm{~Bq} / \mathrm{m}^{3}$ despite its waters being in principle affected by two nuclear power plants [7].

Table 2 gives the mean annual values $\left(\mathrm{Bq} / \mathrm{kg} \mathrm{d}\right.$.w.) of ${ }^{137} \mathrm{Cs}$ in sediments for the different sampling points, the mean values for the time period covered by the study, and their standard deviations. 
Table 2: Annual average values of ${ }^{137} \mathrm{Cs}$ concentrations $(\mathrm{Bq} / \mathrm{kg}$-dry) in sediments of the Tagus River

\begin{tabular}{|l|l|l|l|l|l|}
\hline Year & Arrocampo & Torrejón & V.V. Rodao & Fratel & Valada \\
\hline 1994 & 1.0 & 4.3 & 1.3 & 0.5 & 0.7 \\
1995 & 0.9 & 4.4 & 2.1 & 0.8 & 0.5 \\
1996 & 2.1 & 6.4 & 2.5 & 2.4 & 1.6 \\
1997 & 2.4 & 8.2 & 3.1 & 1.8 & 0.7 \\
1998 & 2.0 & 6.2 & 3.8 & 2.5 & 1.6 \\
1999 & 2.1 & 7.7 & 1.8 & 1.2 & 1.0 \\
\hline Total Average & $1.75 \pm 0.80$ & $6.20 \pm 1.93$ & $2.42 \pm 1.27$ & $1.53 \pm 1.39$ & $1.03 \pm 0.86$ \\
\hline
\end{tabular}

Unlike the case of the waters, for the ${ }^{137} \mathrm{Cs}$ values in sediments there was no relationship between the magnitude of the concentrations found and the proximity of the source term, in this specific case, of the ANPP. Therefore, the capacity for adsorption of these radionuclides has more influence on its level in sediments than the value of its concentration in the water, which is in contact with the sediment. The said adsorption capacity is in general determined by the mineralogical composition and size of the particles forming the sediment. At the Arrocampo and Torrejón points the sediments are of a limestone type although the percentage of fine-grained particles (smaller than $0.2 \mathrm{~mm}$ ) is much greater at Torrejón [8]. In the Portuguese zone of the river, however, V.V. Rodao, Fratel and Valada, the sediments are of a sandy type and with similar grain sizes amongst the three [1].

Other workers too find results, which are unrelated to the proximity of a nuclear power station, but are related to the sediment's mineralogical composition. Thus for example, our sediment results are lower than those detected along the Rumanian sector of the Danube River in 1994, where Mihai et al. [9] repott values between 2 and $40 \mathrm{~Bq} / \mathrm{kg} \mathrm{d}$.w., with no relationship to the proximity of the Koslodui nuclear power station in Bulgaria, but on the contrary a relationship with the mineralogical composition of the sediment $-10 \mathrm{~W}{ }^{137} \mathrm{Cs}$ concentrations were found in sediments extremely poor in clay minerals and higher values when the mineralogical composition of these sediments was richer in illite and vermiculite. Our values are also lower than those reported by Holgye et al. [10] of between 8 and $28.2 \mathrm{~Bq} / \mathrm{kg} \mathrm{d.w}$. in sediments of the River Vltava affected by a nuclear research institute, for the years 1995-96, even though the nuclear power plant at Temelín in the Czech Republic had not yet started operation.

\subsection{Interaction between the water and the sediment}

Distribution coefficients were evaluated in order to compare the radionuclide concentrations in sediment and in water. The distribution coefficient, $C_{d}$, in general is defined by the ratio $\mathrm{Bq} / \mathrm{kg}$ of dry sediment to $\mathrm{Bq} / \mathrm{l}$ of water. In the present study, we use the cross-correlation function, $\mathrm{CCF}(\mathrm{K})$, to obtain a prior estimate of the time the caesium takes to move from water to sediments, or vice vers $a$ on the basis of its temporal evolution at each sampling point. This $\mathrm{CCF}(\mathrm{K})$ function estimates the correlation between two time series corresponding to same sampling point. One, $A(w, t)$, corresponds to the time series of the ${ }^{137} \mathrm{Cs}$ levels measured in water. The other, $A(s, t)$, corresponds to the ${ }^{137} \mathrm{Cs}$ levels measured in sediments, whose values are shifted in time with respect to the first series as a function of the lag $K$ [11]. Given our monthly sampling frequency, we increased the values of the lag by steps of 1 month. The parameter $N$ is the number of experimental points making up each time series, 72 in our case.

$$
C C F(K)=\frac{\sum_{t=1}^{t=N} A(w, t) A(s, t+K)}{\sqrt{\left(\sum_{t=1}^{t=N} A(w, t)\right)^{2}\left[\sum_{t=1}^{t=N} A(s, t+K)\right)^{2}}}
$$

This method is particularly useful to determine whether two time series are correlated (the case when $\mathrm{CCF}$ is significantly different from zero), and, if so, whether the first leads to the second or vice versa. The results of the cross-correlation analysis allow us to obtain the lag in months, $K_{M}$, of the final sediment series with respect to the initial water series, for which the greatest value of the cross- 
correlation function $\mathrm{CCF}\left(K_{M}\right)$ is obtained. The calculations were performed using the program STATGRAPHICS [12].

From the $K_{M}$ value for each sampling point, we determined the distribution coefficient by means of the expression:

$$
C_{d}=\frac{\sum_{t=1}^{t=N} A\left(s, t+K_{M}\right) / A(w, t)}{N}
$$

The results are summarized in Table 3 . From this table, one first observes that at all the sampling points one obtains a value of CCF $\left(K_{M}\right)$ which is significantly different from zero. This indicates that, at all these points, the values of ${ }^{137} \mathrm{Cs}$ in water and in the sediments are correlated. Secondly, one observes that the migration of radiocaesium between the water and the sediment at all the sampling points occurs within a one-month time interval. Thirdly, one deduces that at Torrejón, as $K_{M}<0$, the sediment radiocaesium time series affects, in this case with a one month lag, the water radiocaesium values. This is the contrary to the case for the rest of the sampling points, where it is the values of ${ }^{137} \mathrm{Cs}$ in water, which affect the values determined in the sediments. Fourthly, at Fratel, a negative sign for the greatest value of the cross-correlation function for $K_{M}=0$ indicates a possible inverse dependence of the levels of the sediment ${ }^{137} \mathrm{Cs}$ series with respect to the values of the conditioning series of this radionuclide's activities in the water. I.e., the greater the ${ }^{137} \mathrm{Cs}$ concentrations in the water, the lower are those that are found in the sediments, or vice versa. This possibly reflects a combined effect of the specific characteristics of the sediments at this sampling point and the small input of ${ }^{137} \mathrm{Cs}$ during the study period compared with that during the 1960s from historical fallout, so that any increase in one of the two receptor media occurs at the cost of a decrease in the other. This is not the case at the other sampling points, since the positive values obtained for CCF $\left(K_{M}\right)$ predict a direct interdependence of the ${ }^{137} \mathrm{Cs}$ concentrations in water and in sediments.

Table 3. Results of the cross-correlation analysis, with indication of the lag, $K_{M}$, in months, corresponding to the maximum value of the cross-correlation function, $C C F\left(K_{M}\right)$, and of the distribution coefficient, $C_{d}$, with their standard deviations.

\begin{tabular}{|c|c|c|c|}
\hline Sampling points & Lag $=\mathrm{K}_{M}$ (month) & $\mathrm{CCF}\left(\mathrm{K}_{M}\right)$ & $\mathrm{C}_{d}\left(10^{+3}\right)$ \\
\hline Arrocampo & 1 & 0.31 & $0.65 \pm 0.45$ (S.D.) \\
Torrejón & -1 & 0.20 & $2.5 \pm 1.2$ (S.D.) \\
V.V. Rodao & 0 & 0.13 & $4.4 \pm 7.1$ (S.D.) \\
Fratel & 0 & -0.19 & $4.1 \pm 10$ (S.D.) \\
Valada & 1 & 0.12 & $1.8 \pm 1.9$ (S.D.) \\
\hline
\end{tabular}

From Table 2, one also deduces the great variability in value of the distribution coefficients, indicating the different degree of adsorption of caesium onto the sediments of the different sampling stations. The sediments with the least adsorption capacity are those of Arrocampo, and those with the greatest adsorption capacity (with values very similar to each other) are the points belonging to the Fratel reservoir, V.V. Rodao and Fratel. This is due to the different type and granulometric composition of the sediments at the different stations, as was remarked on above. Nevertheless, the values that we obtained are within the range of those normally reported in the literature [13].

\section{Acknowledgments}

The authors are grateful to the Consejería de Educación, Ciencia y Tecnología (proyect IPR00D001) and to the Agricultura y Medio Ambiente (Convenio de Vigilancia Radiológica Ambiental) of the Junta of Extremadura for financial support. 


\section{References} 663.

[1] Carreiro M. C. V., Bettencourt, A.O. and Sequeira M. M. A., Radioprotection 26 (1991) 649.

[2] Baeza A., Del Río M., Miró C., and Paniagua J., J. Radioanal. Nucl. Chem. 152 (1991)175-188.

[3] Baeza A., Brogueira A.M.,Carreiro M.C.V., García E., Gil J.M., Miró C, Sequeira, M.M. and Teixeira M.M.R., Water Res. 35 (2001) 705 -714.

[4] Fukai R., Ballestra, S., Thein, M.,Guion, J., Input of transuranic elements through rivers into the Mediterranean sea. In Impacts of Radionuclide Releases into the Marine Environment (IAEA, IAEA-SM. 248/125, Viena 1981) pp. 3-14.

[5] Kanivets V.V., Voitsekhovitch O.V., Simov V.G. and Golubeva Z.A., J. Environ. Radioactivity 43 (1999) 121-135.

[6] Vakulovsky, S.M., Kryshev I.I., Nikitin A.I.,Savitsky Y.V., Malyshev S.V. and Tertyshnik E.G, J. Environ. Radioactivity, 29 (1995) 225-236.

[7] Pujol Ll. and Sánchez-Cabeza J.A., J. Environ. Radioactivity 51 (2000) 181-210.

[8] Albareda, J.M., Mapa de suelos de la provincia de Cáceres (Instituto Nacional de Edafología y Agrobiología, Consejo Superior de Investigaciones Científicas, CSIC, Madrid, 1970) pp 48- 69. 131.

[9] Milhai S., Shaw G., Hurtgen Ch. and Georgescu I.I., J. Radioanal. Nucl. Chem. 227 (1998) 129.

[10] Hölgye Z., Foltánová S. and Filgas L., J. Radioanal. Nucl. Chem. 241 (1999), 601-604.

[11] Aguirre A., Introducción al tratamiento de series temporales (Díaz de Santos Publisher, Madrid, 1994) pp 36-55.

[12] STATGRAPHICS, User's Guide. Statistical Graphics Corporation, STSC, 1986.

[13] Coughtrey P.J. and Thorne M.C., Radionuclides Distribution and Transport in Terrestial and Aquatic Ecosystems, A. Critical Review of Data, Vol. 1 (Balkema A.A., (Ed.) Academic Press, Rotterdam, 1983) pp 225-229. 